\title{
Linking Hope and Emotional Creativity: Meditational Role of Positive Affect
}

\author{
Dhruvata Sharma $^{1}$, Dr. Roopa Mathur ${ }^{2}$
}

\section{ABSTRACT}

The study was conducted to examine a potential link between Hope and Emotional creativity (EC). In this context, Positive affect (PA) was explored as a mediator in the relationship between aforementioned variables. A sample of 300 undergraduate students from different streams namely- Fine arts, Fashion \& Jewellery designing, Advertising and Conventional courses (B.A, B.Sc., B.Com.) was selected for the purpose. The results revealed that there was a significant positive correlation between Hope and EC ( $r=0.121, \mathrm{p}<0.05)$; Hope and PA ( $r=0.446, p<$ $0.01)$ and PA and EC ( $r=0.194, \mathrm{p}<0.01)$. Regression analyses and Sobel- $\mathrm{z}$ test were used to test the research hypotheses. Mediation analyses revealed that Positive affect fully mediated the pathway between Hope and Emotional creativity.

Keywords: Hope, Positive Affect, Emotion, Creativity, Emotional Creativity

All information to the brain comes through our senses, and when this information is overpoweringly stressful or emotional, instinct take over and our ability to act is restricted to the flight, fight, or freeze response. Therefore, to have access to the wide range of choices and the ability to make good decisions, we need to be able to bring our emotions into balance at will.

EC combines emotion and cognition in ways that are useful for the individual. It involves the skill to deviate from the common and produce a novel emotional reaction. By learning to use the emotional and cognitive part of our brain together, we can expand our thought action repertoire and deal with emotional situations more effectively.

Life of young people is subject to the usual vicissitudes of academic life, friendship, romantic relationships and career etc. The increasing number of cases of depression and suicide among young people are indicators that many of them are unable to deal with these emotional ups and

\footnotetext{
${ }^{1}$ Research Scholar, Department of Psychology, The IIS University, Jaipur, India

${ }^{2}$ Professor, Department of Psychology, The IIS University, Jaipur, India

*Responding Author

(C) 2016 I D Sharma, R Mathur; licensee IJIP. This is an Open Access Research distributed under the terms of the Creative Commons Attribution License (http://creativecommons.org/licenses/by/2.0), which permits unrestricted use, distribution, and reproduction in any Medium, provided the original work is properly cited.
} 


\section{Linking Hope and Emotional Creativity: Meditational Role of Positive Affect}

downs. The need is for learning new skills and ways to deal with them effectively. EC might be one of those skills.

If EC can be enhanced it will have a positive impact on overall personality and functioning of the individual. Very few empirical studies have been conducted in this field as it is a relatively new concept in context of emotions. Most of the studies done pertain to relationship of emotional creativity with factors like Emotional intelligence, Personality and Cognitive abilities. Therefore it occurred to the researcher to explore the concept of Emotional Creativity with positive variables like Hope and Positive affect.

\section{Emotional creativity:}

"Creativity" refers to those aspects of a person or process that contribute to a response that is judged to be novel, effective, and authentic.

This definition of creativity can be applied directly to the emotions. Specifically, an emotional response is creative if it is in some way novel with respect to the individual or group; if it is effective in enhancing the well-being of the individual and/or society; and if it is authentic, that is, a reflection of the individual's own self.

Novelty: an emotional response may be novel in any of the three ways; first a newly acquired response may be novel for the individual, yet quite standard for the group. Second, an already acquired response, one that is standard within the society, may be refined and applied in a novel ways. Third, a completely new and different emotional syndrome may be developed, one that is not standard for the culture.

Effectiveness: no matter how novel an emotional response might be, it must also be of some value to the individual or group. The emotionally creative response should be adaptive and effective.

Authenticity: the creative product should reflect in some way individual's own values and beliefs about the world. Emotional creativity- to the extent that it meets the criteria of authenticitynecessarily involves self-creation.

Thus, we can say that "Emotional creativity is expressing oneself (authenticity) in new and unique ways (novelty), such that one's personal horizons are expanded and interpersonal relationships are enhanced (effectiveness).” (Aveill and Nunley 1992)

\section{Positive Affect}

Paul Meehl's examination of "hedonic capacity" was first major theoretical step forward in field of positive emotions. Meehl suggested that "clinicians and theoreticians ought to consider 


\section{Linking Hope and Emotional Creativity: Meditational Role of Positive Affect}

seriously the possibility, that not only are some people born with more cerebral 'joy-juice' than others but also that this variable is fraught with clinical consequences” (Meehl 1975). Meehl also suggested that individual contrasts in positive emotionality were to a large extent discrete and distinguishable from negative emotions.

In backing of Meehl's contention, many investigators have ascertained that two mainly autonomous aspects- negative affect \& positive affect make up the essential aspects of emotional experiences.

Positive affect mirrors the degree to which one encounters positive emotions like joy, interest and alertness etc; on the contrary the negative affect measurement embodies the degree to which an individual experiences negative emotions such as fear, anger, sadness and guilt. Both of these states can be measured either as a fleeting state or as a long-term trait (in which case they typically are referred to as "negative affectivity" and "positive affectivity")

\section{Hope}

"When we meet real tragedy in life, we can react in two ways--either by losing hope and falling into self-destructive habits, or by using the challenge to find our inner strength."

- Dalai Lama XIV

Unlike other positive emotions, hope often occurs as the result of a negative situation in which an individual desires a positive resolution. Hope can also said to be a general perception that one's goal can be achieved. Hope is that fuel which drives individuals to succeed in unfavourable circumstances. In lay man's term hope is considered to be an affective occurrence i.e. an emotion experienced when all convenient ways to attain a desirable goal have been exhausted.

Snyder (1991) reconceptualises hope as "a process through which individuals actively pursue their goals and not as a passive emotional phenomenon. Hope is a goal-directed cognitive process."

"Hope is a goal-focused cognitive process that is conceptualized by three necessary and interactive components: goals, agency thinking, and pathways thinking” (Snyder, Feldman, Shorey, \& Rand, 2002).

Goals: Human behaviour is mainly goal- directed. These goals can either be short-term or longterm but they should be significantly important to the individual to occupy conscious thoughts. Also, the nature of goals should be attainable yet challenging.

However, before an individual indulges in goal attainment behaviour, he has to engage himself in two other cognitive actions: pathways and agency thinking. 
Pathways thinking: Individuals need to produce conceivable paths to accomplish their goals. Pathways' thinking is an individual's perceived ability to generate effective routes to achieve required goals. Since some of these routes may not succeed because of possible deterrents, people with high levels of hope create multiple routes to achieve their goals and thus are described as "flexible thinkers". Whereas people with low levels of hope does not represent same sort of flexibility and becomes disheartened if their routes gets blocked.

Creating pathways is a crucial step in the process of attaining goal but it remains trivial without proper spur to apply these pathways. Here comes the role of the last component of hope-theory i.e. Agency thinking.

Agency thinking: it is the apparent capacity to utilize one's pathways in order to accomplish the desired goals. This component is significantly important when an individual experiences a hindrance in goal attainment. It motivates the person to continue in pursuit of goal, by choosing and applying alternatives to sustain the pathways.

\section{METHOD}

\section{Objectives:}

1) To study the relationship between Hope and Emotional Creativity

2) To study the relationship between Positive affect and Emotional Creativity

3) To study the role of Positive affect as mediator variable between Hope and Emotional Creativity.

\section{Hypotheses:}

- $\quad$ H1: Hope will be positively correlated to Emotional Creativity

- $\quad$ H2: There will be a positive correlation between Hope and Positive Affect

- $\quad$ H3: Positive Affect will be positively correlated to Emotional Creativity

- H4: The relationship between Hope and Emotional Creativity will be mediated by Positive Affect

\section{Sample:}

The sample of the study consisted of 300 male and female undergraduate students in the final year from different programmes viz. Fine arts, Advertising, Jewellery \& Fashion designing, Science, Social Science and Commerce. These students were selected with the following criteria of inclusion and exclusion:

\section{- CRITERIA OF INCLUSION}

1) Students of upper middle and upper socio-economic background with an urban domicile

2) Final year undergraduate students

3) Students within the age group of 20 - 23 years

\section{- CRITERIA OF EXCLUSION}

1) Dropouts or students repeating the final year of the degree course

(C) The International Journal of Indian Psychology, ISSN 2348-5396 (e)| ISSN: 2349-3429 (p) | 53 


\section{Linking Hope and Emotional Creativity: Meditational Role of Positive Affect}

2) Students with physical disability or with history of psychological ailments.

3) Students of professional and technical courses

In the present study purposive sampling technique was used. When one uses judgment and planned efforts to obtain a representative sample, that includes typical areas or groups, then it is termed as purposive sampling. In this type of sampling, one picks the cases to include in the sample that is satisfactory in relation to one's needs. Hence, this type of sampling is convenient and time saving.

\section{Design of the study}

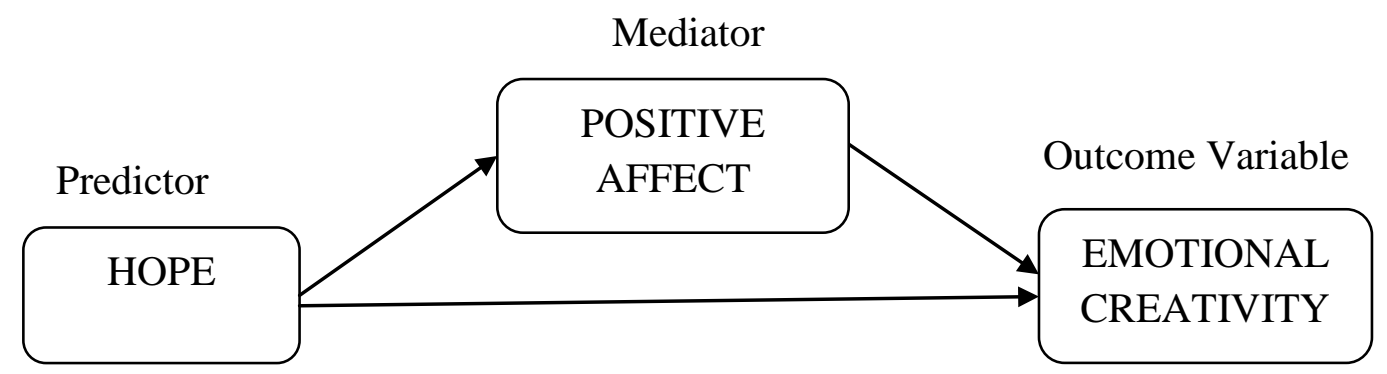

\section{Fig: diagram showing the design of the study}

The design of the study was causal research design as the focus was on investigating the causal effect of Hope on Emotional creativity, which was assumed to be mediated through Positive Affect.

\section{Measures}

In this study the following tests were used for data collection

1) Emotional Creativity Inventory (Averill, 1999)

2) State Hope Scale (Snyder, 1995)

3) Positive Affect Negative Affect Scale (Watson, 1988)

\section{Procedure:}

Initially permission was taken from authorities of various Universities then based on the criteria of inclusion and exclusion students were selected. The selected students were contacted personally and set of questionnaire was given to them. All the tests in the set were paper- pencil self report measures. Students were asked to read the instruction and give their responses on likert type scale. The tests were administered in a group setting and order of administration was random. Thereafter, the results were compiled and trend was studied. 


\section{Statistical Analyses}

For the purpose of statistical analysis, SPSS 'Statistical Package for Social Sciences' version 21.0

Following analyses were computed.

(a) Karl Pearson's Coefficient of correlation

(b) Regression and Mediation analysis: For meditational analysis, steps for testing of mediation as described by Barron \& Kenny (1986) were followed.

(c) Sobel test: It is used to test the significance of mediation effect. For the analyses, procedures and macro given by Preacher and Hayes (2004) were followed strictly.

\section{RESULT}

Table 1.1 Mean, S.D and Pearson correlation matrix $(n=300)$

\begin{tabular}{|llllll|}
\hline Variables & Mean & SD & $\mathbf{1}$ & $\mathbf{2}$ & $\mathbf{3}$ \\
\hline 1.Hope & 32.75 & 6.65 & 1 & - & - \\
2. PA & 35.35 & 6.79 & $0.44^{* *}$ & 1 & - \\
3.EC & 102.23 & 9.32 & $0.12^{*}$ & & 1 \\
\hline
\end{tabular}

*Significant at 0.05 level ** Significant at 0.01 level

Mediating effect of Positive Affectivity (PA) between Hope and Emotional Creativity (EC)

A. Path coefficient estimates

Table 1.3 Regression coefficients to predict EC from Hope

\begin{tabular}{|c|c|c|c|c|c|c|}
\hline & \multirow[t]{2}{*}{ Model } & \multicolumn{2}{|c|}{$\begin{array}{c}\text { Unstandardized } \\
\text { Coefficient }\end{array}$} & \multirow{2}{*}{$\begin{array}{c}\begin{array}{c}\text { Standardized } \\
\text { Coefficient }\end{array} \\
\text { Beta } \\
\end{array}$} & \multirow[t]{2}{*}{$\mathbf{t}$} & \multirow[t]{2}{*}{ Sig. } \\
\hline & & B & Std. Error & & & \\
\hline \multirow{2}{*}{1} & (Constant) & 96.667 & 2.690 & & 35.932 & .000 \\
\hline & Hope & .170 & .081 & .121 & $2.108 *$ & .036 \\
\hline
\end{tabular}

[ NOTE: Fit for model $\mathrm{R}^{2}=0.015$; Adjusted $\mathrm{R}^{2}=0.011 ; \mathrm{F}(1,298)=4.446, \mathrm{p}<0.05$ ]

Table- 1.3 indicates that $1.1 \%$ variance in EC is accounted for by Hope. The unstandardized regression coefficient for the prediction of EC from Hope $(\mathrm{c}=0.170)$ is statistically significant $[\mathrm{t}$ $(298)=2.108, p<0.05]$ 
Linking Hope and Emotional Creativity: Meditational Role of Positive Affect

Table 1.4 Regression Coefficients to predict PA from Hope

\begin{tabular}{|c|c|c|c|c|c|c|}
\hline \multirow{2}{*}{\multicolumn{2}{|c|}{ Model }} & \multicolumn{2}{|c|}{ Unstandardized Coefficient } & \multirow{2}{*}{$\begin{array}{c}\begin{array}{c}\text { Standardized } \\
\text { Coefficient }\end{array} \\
\text { Beta }\end{array}$} & \multirow[t]{2}{*}{$\mathbf{t}$} & \multirow[t]{2}{*}{ Sig. } \\
\hline & & B & Std. Error & & & \\
\hline \multirow{2}{*}{1} & (Constant) & 20.411 & 1.767 & & 11.551 & .000 \\
\hline & Hope & 456 & .053 & 446 & $8.623^{* *}$ & .000 \\
\hline
\end{tabular}

[NOTE: Fit for model $\mathrm{R}^{2}=0.199$; Adjusted $\mathrm{R}^{2}=0.196 ; \mathrm{F}(1,298)=74.358, \mathrm{p}<0.001$ ]

Hope accounts for $19.6 \%$ variance in PA. The unstandardized coefficients $(\mathrm{a}=0.456)$ has been found to be statistically significant [t $(298)=8.623, \mathrm{p}<0.001]$

Table 1.5 Regression Coefficients to predict EC from Hope and PA (mediating variable)

\begin{tabular}{|c|c|c|c|c|c|c|}
\hline \multirow{2}{*}{\multicolumn{2}{|c|}{ Model }} & \multicolumn{2}{|c|}{ Unstandardized Coefficient } & \multirow{2}{*}{$\begin{array}{c}\begin{array}{c}\text { Standardized } \\
\text { Coefficient }\end{array} \\
\text { Beta }\end{array}$} & \multirow[t]{2}{*}{$\mathbf{t}$} & \multirow[t]{2}{*}{ Sig. } \\
\hline & & B & Std. Error & & & \\
\hline \multirow{3}{*}{1} & (Constant) & 91.758 & 3.200 & & 28.674 & .000 \\
\hline & Hope & .060 & .089 & 043 & .675 & 500 \\
\hline & PA & 241 & .087 & 175 & 2.762 & .006 \\
\hline
\end{tabular}

a. Dependent Variable: emotional creativity

[NOTE: Fit for model $\mathrm{R}^{2}=0.039$; Adjusted $\mathrm{R}^{2}=0.033 ; \mathrm{F}(2,297)=6.086, \mathrm{p}<0.01$ ].

Hope and PA account for $3.3 \%$ of variance in EC and predict the same significantly. The unstandardized coefficients for path $\mathrm{b}=0.241$, $\mathrm{t}(297)=2.762$, $\mathrm{p}<0.01$; and path $\mathrm{c}^{\prime}=0.060$, $\mathrm{t}$ $(297)=0.675, p=0.500$

B. Evaluating statistical significance using Sobel test

Table 4.6 Mediating analyses of PA between Hope and EC

\begin{tabular}{|l|l|l|l|}
\hline Variable name & Beta & t-value & P-value \\
\hline Hope $\rightarrow$ EC & 0.1698 & 2.1085 & 0.0358 \\
\hline Hope $\rightarrow$ PA & 0.4560 & 8.6231 & 0.0000 \\
\hline $\begin{array}{l}\text { PA } \rightarrow \text { EC } \\
\text { (controlling Hope) }\end{array}$ & 0.2405 & 2.7619 & 0.0061 \\
\hline $\begin{array}{l}\text { Hope } \rightarrow \text { EC } \\
\text { (controlling PA) }\end{array}$ & 0.0601 & 0.6751 & 0.5001 \\
\hline \multicolumn{1}{c|}{ Indirect effect } & 0.1097 & $\begin{array}{l}\text { Z-value } \\
2.6143\end{array}$ & 0.0089 \\
\hline
\end{tabular}

PA = Positive Affect

$\mathrm{EC}=$ Emotional Creativity

(c) The International Journal of Indian Psychology, ISSN 2348-5396 (e)| ISSN: 2349-3429 (p) | 56 
Results in the above table indicate that (i) EC is predicted by Hope, (ii) Hope predicts PA, (iii) EC is predicted by PA irrespective of whether individual is hopeful or not (iv) with controlling for PA, the relationship between Hope and EC became insignificant $(p=0.500)$. Hence the results point at full mediation such that PA completely impacts the relationship between Hope and Emotional Creativity of a person. This is also supported by z- value for the indirect effect (2.6143) which was significant $(\mathrm{p}<0.01)$ indicating that the effect of Hope on Emotional creativity when mediated by Positive Affect can be judged statistically significant.

\section{DISCUSSION}

\section{Direct Pathways:}

(i) Hope and Positive Affectivity (PA)

Most positive emotions arise when we feel safe and satiated. Hope is the exception. It comes into play when our circumstances are dire - things are not going well or at least there's considerable uncertainty about how things will turn out.

The first hypothesis stated that there will be a positive relationship between Hope and Positive Affect. The results supported the hypothesis and significant positive correlation has been found between the two variables $(r=0.446, p<0.01$ ). Regression analysis further shows that $19.6 \%$ of variance in PA is accounted for by Hope which is significant at $\mathrm{p}<0.001$ level. This indicates that the people with higher level of Hope will show more Positive Affectivity.

Several studies in the past have examined the relation between Hope and the component parts of well being including affect. Higher Hope is associated with reports of higher positive and lower negative affect (Snyder, Harris et al 1991)

Steffen and Smith (2013) examined the interplay of Hope and affect and found that Hope was significantly related to same day reports of positive affect and significantly predicted next day positive affect. The relation between Hope and positive affect did not vary in relation to stress. The results from this study suggest Hopeful thought predicts Positive Affectivity.

There is evidence that the association between measures of Hope and PA is large in magnitude, ranging from 0.52 to 0.77 (Feldman and Snyder, 2005; Mascaro and Rosen, 2005). People with higher levels of Hope endorse a greater frequency and intensity of positive emotions and on the contrary, fewer and less intense negative emotions (Snyder et al., 1996).

Positive affect is a component of the approach- oriented behavioural facilitation system, which directs organism towards situations and experiences that potentially may yield pleasure and rewards. Within the theoretical framework given by Snyder et al (1991) Hope and positive affect are hypothesized to be related in two ways viz. Positive affect results from goal (sub-goal) success and over time, repeated successful goal pursuits tend to result in a consistent positive 


\section{Linking Hope and Emotional Creativity: Meditational Role of Positive Affect}

mood disposition. The relation of Hope and PA works in a chain- Hope focuses on achieving goals, when goals are achieved individual experiences positive emotions, which further motivates the person to work actively in direction of other goals.

Both Hope and PA act as an antidote for the lingering effects of negative thoughts and emotions. A person who experiences more positive emotions is less likely to be depressed, stressed or anxious. Similarly, Hopeful individuals focus more on how to deal with the obstacles, rather than focussing on the problems. Positive emotions undo the effects of negative emotions as stated by undoing hypothesis (Fredrickson \& Leverson, 1998; Fredrickson et al 2000). Both Hope and PA increase positive thinking in the individual and act as a buffer.

Hope can influence one's emotions as they are a consequence of goal-directed behaviour and thoughts. When an individual makes a progress in achieving a goal or overcomes the barriers in attaining the goals, he/she experiences positive emotional state. The data of the study converge with these claims that a higher level of Hope is predictive of positive dispositions or mindsets.

\section{(ii) Positive Affect (PA) and Emotional Creativity (EC)}

The hypothesis stated that there will be a positive relationship between PA and EC. The results supported the hypothesis and significant positive correlation has been found between the two variables $(r=0.194, p<0.01)$. Regression analysis further shows that $3.5 \%$ of variance in EC is accounted for by Positive affect which is significant at 0.001 level. This suggests that if a person has greater Positive Affect he/she will be emotionally more creative.

Positive Affectivity is an attribute that describes how humans experience positive emotions and interact with others and with their surroundings. It is an integral part of day to day life. It helps to process emotional information efficiently and accurately. People with high Positive Affect are typically energetic, enthusiastic, confident, alert and active.

From the above discussion it can be suggested that Positive Affectivity enhances emotional creativity because positive feelings increase the tendency to combine material in new ways and to see relatedness between divergent stimuli. This occurs because the large amount of cognitive material cued by the positive affective state results in a broader perspective.

Many studies on cognitive processes such as memory, decision making, and problem solving have shown that positive affect is generally facilitating. For example, it enables flexible thinking and creative problem solving on tasks that otherwise are very difficult, and it promotes thinking that is not only efficient but also careful, open-minded, and thorough. (Isen, Daubman and Nowicki 1987). Furthermore, the experience of positive affect is known to promote social interaction, helpfulness, generosity, and social responsibility-and it does so without undermining attention to a person's own long-term welfare. 


\section{Linking Hope and Emotional Creativity: Meditational Role of Positive Affect}

\section{Indirect pathway:}

(i) Hope and Emotional Creativity(EC) mediating role of Positive Affect(PA)

On performing mediation analysis, it was observed that the path coefficient from Hope to Emotional Creativity $(c=0.170)$ dropped to $\left(c^{\prime}=0.060\right)$ and became insignificant $(p=0.500)$ when controlling for Positive Affectivity. This indicates that mediation effect of Positive Affectivity was full. The indirect effect $(\mathrm{z}=2.6143)$ was high and significant $(\mathrm{p}<0.01)$, confirming the presence of a mediating pathway.

Hope, Humour and Happiness are categorized as positive emotions and Positive Affectivity is described as a person's ability to experience positive emotions. The relationships among these variables are best explained by Fredrickson's Broaden and Build Theory of Positive Emotions.

People high on positive affectivity tend to be more open to expansive ideas and willing to look beyond their immediate situation and concerns, they can use this emotional energy for greater creative expression. Since, Emotional creativity requires divergent thinking process and creation of appropriate, and yet authentic, responses. (Jenaabadi, Marziyeh and Dadkan 2015) Positive affectivity forms a bridge between Positive emotions and Emotional creativity. Broaden and Build theory's key proposition is that positive emotions broaden an individual's momentary thought-action repertoire. When he/she experiences positive emotions these broadened mindsets promote discovery of novel and creative actions, ideas and social bonds, which in turn build individual's personal resources; ranging from physical and intellectual resources, to social and psychological resources.

The need for Emotional creativity arises when already existing emotions don't work effectively and an individual is required to expand his personal horizons. EC requires divergence from the norms and pertains to the richness of a person's emotional life. Positive affectivity through positive emotions prepares a ground for emotional creativity to flourish by enhancing divergent thinking and creation of novel ideas in an individual. EC paves the way for an individual striving towards actualization of their potential.

If Hope is ability to see the silver lining on the cloud, Emotional creativity can said to be the capability to create that silver lining.

\section{CONCLUSION}

The present study focussed on exploring the relationship between Hope, Positive affect and Emotional creativity. Results revealed a significant positive correlation between the predictor, criterion ad mediating variable. Also, Positive affect was found to fully mediate the pathway between Hope and Emotional Creativity. Since there is not much literature available exploring relationship of aforementioned variable, this study would add to the body of research. 


\section{Linking Hope and Emotional Creativity: Meditational Role of Positive Affect}

Our society is changing rapidly, because of which our values, culture and family structure are also changing at a very fast pace. Change, be it in any form or field, can initially create confusion, resentment or emotional turmoil. In such situation, learning to be emotionally more creative would help in understanding and expressing our emotions and to deal with them in a unique and novel way. Emotional creativity allows an individual to transform his emotions to better fit his personal needs and requirements. EC suggests a different way of looking at emotions, it can be useful for both therapists/counsellors as well as clients. It would allow them to see the situations from a new perspective and thus deal with it effectively.

\section{Acknowledgments}

The author appreciates all those who participated in the study and helped to facilitate the research process.

\section{Conflict of Interests}

The author declared no conflict of interests.

\section{REFERENCES}

Averill, J. R. (1999). Individual differences in emotional creativity: Structure and correlates. Journal of Personality, 67, 331-371.

Averill, J. R., \& Nunley, E. P. (1992). Voyages of the heart: Living an emotionally creative life. New York: The Free Press.

Baron, R. M., \& Kenny, D. A. (1986). The moderator-mediator variable distinction in social psychological research: Conceptual, strategic, and statistical considerations. Journal of personality and social psychology,51(6), 1173

Feldman, D. B., \& Snyder, C. R. (2005). Hope and the meaningful life: Theoretical and empirical associations between goal-directed thinking and life meaning. Journal of Social and Clinical Psychology, 24(3), 401.

Frederickson, B. L. (1998). What good are positive emotions? Review of General Psychology, 2(3), 300-319.

Frederickson, B. L. (2001). The role of positive emotions in positive psychology: The broadenand-build theory of positive emotions. Journal of American Psychological Association, 54(3), 218-226.

Fredrickson, B. L., \& Levenson, R. W. (1998). Positive emotions speed recovery from the cardiovascular sequelae of negative emotions. Cognition and Emotion, 12, 191-220.

Fredrickson, B. L., Mancuso, R. A., Branigan, C., \& Tugade, M. (2000). The undoing effect of positive emotions. Motivation and Emotion, 24, 237-258.

Isen, A. M., Daubman, K. A., \& Nowicki, G. P. (1987). Positive affect facilitates creative problem solving. Journal of Personality and Social Psychology, 52, 1122-1131.

Jenaabadi, H., Marziyeh, A., \& Dadkan, A. M. (2015). Comparing Emotional Creativity and Social Adjustment of Gifted and Normal Students. Advances in Applied Sociology, 5(03), 111.

(C) The International Journal of Indian Psychology, ISSN 2348-5396 (e)| ISSN: 2349-3429 (p) | 60 


\section{Linking Hope and Emotional Creativity: Meditational Role of Positive Affect}

Mascaro, N., \& Rosen, D. H. (2005). Existential meaning's role in the enhancement of hope and prevention of depressive symptoms. Journal of personality, 73(4), 985-1014

Meehl, P. E. (1975). Hedonic capacity: Some conjectures. Bulletin of the Menninger Clinic, 39, 295-307.

Preacher, K. J., \& Hayes, A. F. (2004). SPSS and SAS procedures for estimating indirect effects in simple mediation models. Behavior research methods, instruments, \& computers, 36(4), 717-731

Snyder, C. R. (1995). Conceptualizing, measuring and nurturing hope. Journal of Counseling and Development, 73, 355-360.

Snyder, C. R., Harris, C., Anderson, J. R., Holleran, S. A., Irving, L. M., Sigmon, S. T., Yoshinobu, L., Gibb, J., Langelle, C., \& Harney, P. (1991). The will and the ways: Development and validation of an individual-differences measure of hope. Journal of Personality and Social Psychology, 60, 570-585.

Snyder, C. R., Sympson, S. C., Ybasco, F. C., Borders, T. F., Babyak, M. A., \& Higgins, R. L. (1996). Development and validation of the State Hope Scale. Journal of personality and social psychology, $70(2), 321$

Steffen, L. E., \& Smith, B. W. (2013). The influence of between and within-person hope among emergency responders on daily affect in a stress and coping model. Journal of Research in Personality, 47(6), 738-747

Watson, D., Clark, L. A., \& Tellegen, A. (1988). Development and validation of brief measures of positive and negative affect: The PANAS scales. Journal of Personality and Social Psychology, 54, 1063-1070.

How to cite this article: D Sharma, R Mathur (2016), Linking Hope and Emotional Creativity: Meditational Role of Positive Affect, International Journal of Indian Psychology, Volume 3, Issue 4, No. 58, ISSN 2348-5396 (e), ISSN: 2349-3429 (p), DIP: 18.01.044/20160304, ISBN: 978-1-365-24976-1 